\title{
Transforming Scientific Results into Educational Materials - Added Value of a Research Project
}

\author{
Yanita Chernogorova ${ }^{1}$, Turgay Kalinov ${ }^{2,3}$, Nikolay Dukov ${ }^{4}$, Kristina Bliznakova ${ }^{4}$, \\ Alexander Zlatarov ${ }^{2,3}$, Nikola Kolev ${ }^{2,3}$, Zhivko Bliznakov ${ }^{1,4}$ \\ ${ }^{1}$ Center for simulation technology and medical equipment, Medical University of Varna, Varna, Bulgaria \\ ${ }^{2}$ Department of General and Operative Surgery, Medical University of Varna, Varna, Bulgaria \\ ${ }^{3}$ First clinic of surgery in UMHAT "Saint Marina", Varna, Bulgaria \\ ${ }^{4}$ Department of Medical Equipment, Electronic and Information Technologies in Healthcare, Medical \\ University of Varna, Varna, Bulgaria
}

\begin{abstract}
In recent years, there has clearly been a trend towards widespread dissemination of scientific results and achievements by sharing them in the form of educational materials. The application of the results of a research project in the education and knowledge development of students, young researchers and scientists, brings an added value to the outcomes of the scientific project. This work aims at contributing to the global process of free access to scientific materials by sharing the experience of a research group from the Medical University of Varna (MUV) in systematizing the results of three research projects, their transformation into educational resources and their application in innovative courses. The consolidated and systematized results of a research project are valuable assets for development of innovative educational materials. These resources, uploaded in a shared online repository, contribute to strengthen the international scientific community networking.
\end{abstract}

DOI: $10.18421 /$ TEM111-14

https://doi.org/10.18421/TEM111-14

Corresponding author: Yanita Chernogorova,

Center for simulation technology and medical equipment,

Medical University of Varna, Varna, Bulgaria.

Email: yanita.chernogorova@gmail.com

Received: 07 October 2021.

Revised: 14 January 2022.

Accepted: 19 January 2022.

Published: 28 February 2022.

(c))BY-NC-ND (C) 2022 Yanita Chernogorova et al; published by UIKTEN. This work is licensed under the Creative Commons Attribution-NonCommercial-NoDerivs 4.0 License.

The article is published with Open Access at https://www.temjournal.com/
Keywords - educational materials, educational methods, research projects, educational resources.

\section{Introduction}

We are witnessing global transformation in a number of areas of our lives - economics, energy, education, etc. These global processes concern inevitably every single country, every single organization. In terms of education, from a strategic point of view, the winning position is reserved for those Higher Education Institutions (HEIs) that are active participants in this process, and not just passively adapting to changes [1]. Therefore, the top management of a HEI should focus on the latest concepts in the policies and strategic documents that it follows. Such a key EU policy is encouraging collaborations between universities, and has made Europe more united, more innovative and more competitive. The Union's aim is to make this process sustainable by creating a European Education Area (EEA) by 2025. The latest Commission Communication on this ambitious goal, published in September 2020, sets out the main steps towards achieving the objectives and intention of actively working with the European Research Area (ERA) for research and innovation [2]. The communication highlights the expected synergy of their collaboration and emphasizes the key role of universities as a link between the two organizations. Moreover, the program for the transformation of HEIs towards consolidation should cover all four missions of the universities: education and research leading to innovation and results for the benefit of society. In this regard, the most significant change perhaps, is in the "Knowledge Triangle" paradigm, which has been extended to a "Knowledge Square", including education, research, innovation and interaction with 
society [3]. The HEIs are recognized as the bearers of these four core tasks. The last added element in the so-called "Knowledge Square" - interaction with society, strengthens the emphasis on the practical applicability of the results of educational activities in higher education. In this context, we can consider the project activity as a prop of all four elements of the new paradigm:

- Quality education can be achieved through project activities;

- Project activity is the appropriate tool, under which to carry out research;

- Innovation origin is a result of scientific project activities;

- Addressing project activities to overcome societal challenges is a way of interaction with society.

The transition from formal education to a broader perspective involves a number of hard and soft skills that people need to acquire and develop throughout their lives in order to achieve professional success [4]. Therefore, Higher Education urgently needs to find better ways to implement effective teaching and learning strategies [5]. A crucial task of the sector is to provide innovative education for students to increase their competitiveness in the labour market [6]. To this end, HEIs should lead the training in current curricula, include innovative teaching methods and provide access to practical experience.

The challenge for teachers is to create a learning climate, in which learners are encouraged to seek new knowledge and master research methods and practical techniques for solving scientific challenges and analyzing different information flows [7]. Research in the field offers support for student innovation by promoting their autonomy during practical lessons [8]. Although successful, this method is not applicable to the training of medical students, and medical universities must seek different methods.

Project-based learning can meet these needs [9] and develop key competencies and skills to implement innovative solutions to health problems. This is because project-based learning is based on the science of active knowledge building [10]. The same conclusions are drawn from the work of Wilhelm et al., where the results support the impact of the implemented projects into the educational process [11]. This method of creating new knowledge allows students to test and achieve their ideas, which stimulates their innovative competences.

Characteristic of the project activity in the academic circles is the scientific beginning and striving to solve the current social challenges. This is an indicator of the relevance of the issues and innovation in the approach, which is a condition for quality in education.
It is no coincidence that European and national mechanisms stimulate the process of involving students in the project activity. For example, the evaluation criteria for project proposals of the Bulgarian National Science Fund are in favour of wider participation of MSc and $\mathrm{PhD}$ students. Similar evaluation standards are included in the internal rules of the HEIs when financing scientific projects.

The relation between training and project activity is expected to be formalized soon through the legal framework in Bulgaria. The latest proposed changes in the Higher Education Act envisage the formalization of the so-called "project" doctoral program or the preparation of $\mathrm{PhD}$ students within the implementation of a research project. The reasons for amending the law indicate the strategic goals of the country to activate basic and applied research in higher education, the development of innovation and entrepreneurial skills of students and teachers and the transformation of research and innovation into an integral part of higher education [12].

This work aims at contributing to the global process of free access to scientific materials by sharing the experience of a research group from the Medical University of Varna (MUV) in systematizing the results of three research projects, their transformation into educational resources and their application in innovative courses.

\section{Method}

The scientific outputs of three research projects running in the period 2012 - 2021 were sufficiently novel and this was a reason to introduce three completely new topics for the students of Medicine and Public Health education in MUV. The projects are related to the development of novel breast imaging techniques and the introduction of robotic surgery at the University Hospital of Varna. The main outcomes of these projects are new software applications, new in-house developed and commercial equipment, new methods and methodologies.

This work concerned BSc and MSc students at the Medical University of Varna, involved in different topics: "3D printing in Medicine", "Applied simulation software in Healthcare" and "Introduction to Robotic Surgery" for the academic year 20202021. Students were involved in practical training using products and equipment, developed or acquired under scientific projects. Specifically, a total of 78 students participated, with the following distribution: 16 in "3D printing in Medicine", 16 in "Applied simulation software in Healthcare" and 46 in "Introduction to Robotic Surgery". The first two topics are from the MSc degree program "Information technologies in Healthcare", while the third one is an elective topic for the BSc students in Medicine. All three topics are newly created and run for the first time in the academic 2020-2021. 


\section{Results and Discussion}

The first product is a software application used by students to realistically model anthropomorphic breast phantoms and generate $\mathrm{x}$-ray images by simulating $\mathrm{x}$-ray imaging modalities, such as computed tomography, radiography, and limited angle tomography [13]. The computational model of the female breast is an aggregate of breast shape, duct system, Cooper ligaments, texture and abnormalities. The modelling is implemented through a hybrid approach: geometrical primitives and voxel matrices. Figure 1. shows an example of such a model, where the major components, the mammary gland and the adipose tissue, are distinguished. This software application is capable of producing a great variety of breast models with and without lesions, and their $\mathrm{x}$-ray images in any modelled x-ray imaging modality. This software is the heart of the MSc topic "Applied simulation software in Healthcare", where students learn the anatomy of the breast and the projection of this anatomy in a mammography image. They are also engaged with student projects during which, the learners develop their own x-ray imaging technique and study its performance in respect to the visibility of different breast lesions.

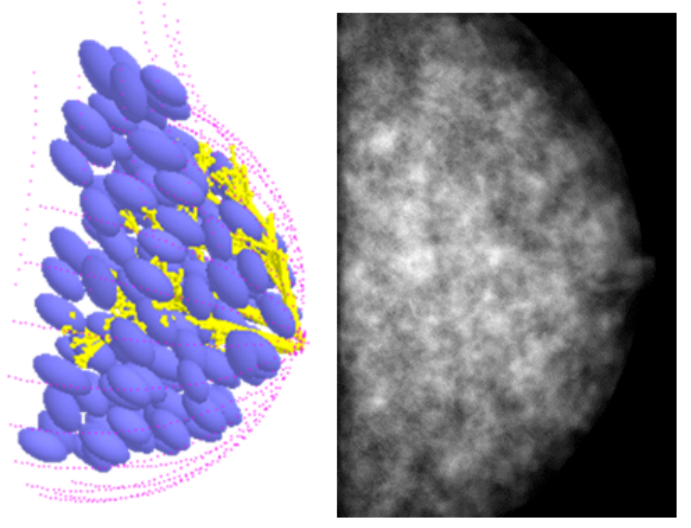

Figure 1. A computational breast model of a female breast and generated $x$-ray mammography image

The second software application is used to model $\mathrm{x}$-ray images of the phantoms created by the users [14]. This software tool is the main tool for modelling phantoms based on geometrical primitives, as well as, it is used to generate $3 \mathrm{D}$ voxelized models from medical images. An example is shown in Figure 2. The software is used by the students to design their phantoms, dedicated for x-ray imaging and to study how the different factors such as, $x$-ray tube voltage and current, geometrical distances, detector and object properties, influence the quality of the x-ray images.

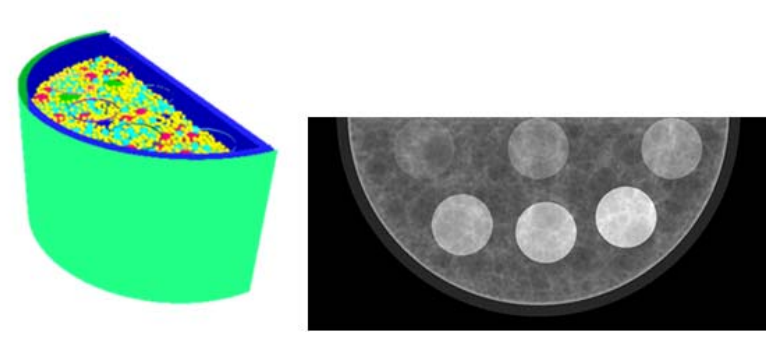

Figure 2. Computational $3 D$ phantom and the generated $x$-ray image

Furthermore, in the topic " $3 \mathrm{D}$ printing in Medicine", the experience and the equipment gained from those projects in the field of $3 \mathrm{D}$ printing for medical applications is transferred into training of the students. The software tool for modelling the female breast (Figure 1.) is used as a starting point. The knowledge that the students gained with this modelling software, is further extended by means of a specific task, to create a 3D printable anthropomorphic breast model. The targeted 3D printing technology is Stereolithography (SLA) with bottom-up printing. Creating the computer model is the first step of many, in order to achieve a successful 3D printed model. With the aim of generating the needed stereolithography (stl) file of the model for printing, the raw data of the breast model is loaded into ImageJ (https://imagej.nih.gov/ij/), which the students use for visualizing, post processing, and exporting the model to a stl file, suitable for 3D printing. With the purpose of further increasing the chances for a successful print, the students were introduced to software tools such as MeshLab and Blender, all free and open source software's, which give the possibility for additional and more extensive post processing of the models before printing. Finally, the post-processed computational anthropomorphic breast models are loaded into a slicing software, where the students make finale preparations such as, placing the model in a suitable printing position, adding support structures, adjusting the layer height, and slicing the model, thus generating the G-code for the $3 \mathrm{D}$ printer. The whole process from the initial generation of the computational model to its slicing, concludes with 3D printing the physical anthropomorphic breast model, as shown in Figure 3. However, post processing of the physical printed model is required as well, where the students carefully remove the supporting structures. Introduction to other post processing techniques is done as well, such as, sanding, painting and polishing, which depends on the field of application and can be compulsory or optional (an aesthetic finish). 


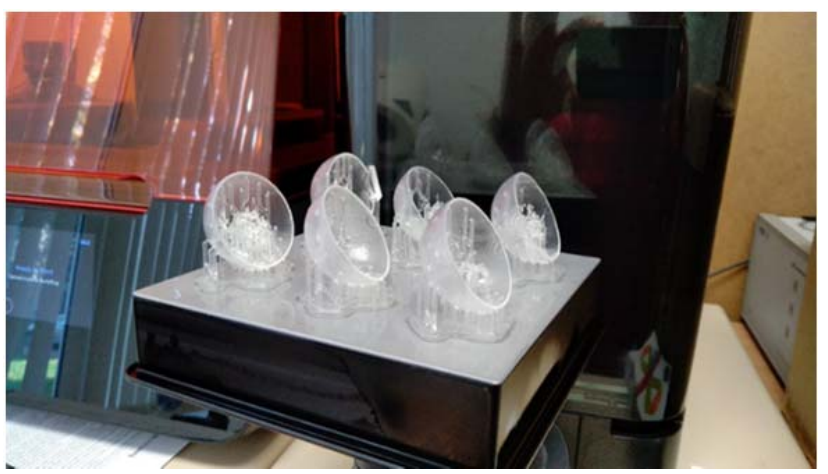

Figure 3. Scaled physical 3D printed anthropomorphic breast models with supporting structures and rafts on the build platform of Form 3 printer, obtained during a research project

Finally, during the summer semester of the academic year 2020-2021, a pilot training of $5^{\text {th }}$ year students on the topic of robotic surgery was conducted on the robotic da Vinci Xi system. The training was divided into two modules: a two-week theoretical module and a two-week practical module. Within one month, 46 students had the opportunity to get acquainted with the da Vinci SimNow Simulator, part of the robotic system da Vinci Xi, acquired under a European project. The simulator is designed to be a training tool that includes various exercises and scenarios, giving the students the opportunity to improve their skills through the da Vinci systems. Exercises with the da Vinci SimNow Simulator recreate the practical work of using the full configuration of the da Vinci system. Figure 4. shows a photo from the training session. None of the students in the training reported any previous experience with a robotic system.

The students who followed the MSc program in "Information Technologies in Healthcare" and total 12 topics in this program were asked the following question: "Which topic provided you with the most valuable knowledge?" at the end of first academic year. The results showed that the methods for modelling the breast and $\mathrm{x}$-ray images obtained the highest evaluation from all topics, which corresponded to $82 \%$ of the students, followed by the practical training on 3D printing technologies with $73 \%$ approval from the students.

For the "Introduction to Robotic Surgery" course, the 46 participants were asked "Is the simulation platform suitable for student training?" at the end of the training. All students, who have completed the first training module with the da Vinci Xi simulator, reported that they are extremely satisfied with the training and are convinced that the simulation platform is appropriate for practical training in robotic surgery. Moreover, $80 \%$ of the students think that the duration of the training is enough to gain initial experience with the system, while $20 \%$ of them think that they need a longer training course.

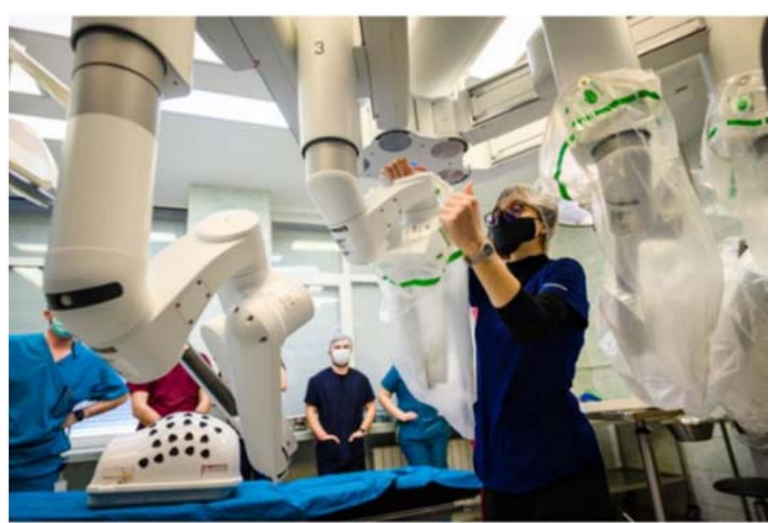

Figure 4. A photo from the robotic surgery training performed in the Robotic Surgery Centre of Competence at the University Hospital of Varna

During the practical training, students developed their own computational breast models. Open source software tools such as, ImageJ were then used to process the generated images and convert them into a suitable format for $3 \mathrm{D}$ printers. Through the use of project-developed software applications in the learning process, students witness the entire process of creating an innovative product - from a computational model to a 3D printed physical model.

The results of the survey, conducted after each semester, showed that the students determined as the most valuable topics those which employ outcomes and products from scientific projects' activities.

All respondents (100\%), who were involved in the first training module with the da Vinci Xi simulator, were very satisfied with the practical training, accomplished in the Robotic Surgery Centre of Competence at the University Hospital of Varna. As a result of the successfully conducted training, students of Medicine from $3^{\text {rd }}, 4^{\text {th }}$, and $5^{\text {th }}$ year can now take advantage of this new opportunity by choosing to be involved in the topic "Introduction to Robotic Surgery". The latter was officially introduced in the curriculum of the students of Medicine as an elective topic.

Educational materials, which contributed to increasing the knowledge level and developing skills in applying innovative methods for modelling breast phantoms, have highest evaluation from $82 \%$ of students. Right after comes the practical training on $3 \mathrm{D}$ printing technologies with $73 \%$ approval from the students.

Consolidation and systematization of project results are a source of innovative training materials that (a) can be reused; (b) may be shared and accessible in an open access repository. Free access to scientific achievements is a long-standing goal of the EU, and the Union is once again demonstrating this through the revitalization of the European Research Area as the New European Research Area.

Along with the acquisition of soft and hard skills, students have increased their interest in research. After the completion of the training, three MSc students in "Information technology in healthcare" 
program participated in ongoing research projects, where they applied their knowledge gained from the training. Students' project participation will result in the development of MSc theses with topics in 3D printed tissue models, novel computational tissue models, dual-energy $\mathrm{x}$-ray imaging techniques, as well as evaluation of the effectiveness of medical simulators in teaching and training of medical students. Graduates' interest in science may grow into an academic career choice, but exploring the relationship between students' engagement in research and their professional path at the university is the subject of future research.

\section{Conclusions}

Reconsidering and reassessing the importance and the role of the project activities in the strategic planning of the HEIs is imperative in the context of a transforming HEI sector oriented towards services for society and economic development.

Project-based learning is based on the science of active knowledge building and this method allows students to test and achieve their ideas, which stimulates their innovative competence and develops their professional and entrepreneurial skills.

The integration of project results into the teaching process is a tool for providing up-to-date educational resources. Advanced teaching methods revealed the possibilities of modern technologies in meeting nowadays' challenges. Universities that update their curricula are highly rated and their students are competitive on the labour market. Therefore, we can conclude that the transformation of scientific products into educational materials has clear benefits for students, universities, industry, and innovation.

\section{Acknowledgements}

Authors T.K., A.Z. and N.K. are supported by the European Regional Development Fund through the Operational Programme "Science and Education for Smart Growth" under contract №BG05M2OP001-1.0020010-C01 (2018-2023). Authors Y.C., N.D., K.B and Z.B are supported by the BNSF, grant agreement DN17/2.

\section{References}

[1]. Shawe, R., Horan, W., Moles, R., \& O’Regan, B. (2019). Mapping of sustainability policies and initiatives in higher education institutes. Environmental Science \& Policy, 99, 80-88.

[2]. Hancharonak, I. I., Nabiulina, L. M., \& Ismadiyarov, Y. U. (2020). New metrics for European Education Area: challenge for higher education management. Retrieved from: https://rep.bntu.by/bitstream/handle/data/87702/152155.pdf? sequence $=1 \quad$ [accessed: 10 July 2021].
[3]. Meissner, D., Gokhberg, L., Kuzminov, Y., Cervantes, M., \& Serger, S. S. (2021). Knowledge Triangle Targeted Science, Technology and Innovation Policy. In The Knowledge Triangle (pp. 315). Springer, Cham.

[4]. Unger, M., Marsan, G. A., Meissner, D., Polt, W., \& Cervantes, M. (2020). New challenges for universities in the knowledge triangle. The Journal of Technology Transfer, 45(3), 806-819.

[5]. Soicher, R. N., Becker-Blease, K. A., \& Bostwick, K. C. (2020). Adapting implementation science for higher education research: the systematic study of implementing evidence-based practices in college classrooms. Cognitive Research: Principles and Implications, 5(1), 1-15.

[6]. Crosling, G., Nair, M., \& Vaithilingam, S. (2015). A creative learning ecosystem, quality of education and innovative capacity: a perspective from higher education. Studies in Higher Education, 40(7), 11471163.

[7]. Bazhenov, R. I. (2019). Arranging Student Scientific Research as an Educational Technology: The Experience of Regional Universities of Russia. Education Research International.

[8]. Martin, P., Potočnik, K., \& Fras, A. B. (2017). Determinants of students' innovation in higher education. Studies in Higher Education, 42(7), 12291243.

[9]. Guo, P., Saab, N., Post, L. S., \& Admiraal, W. (2020). A review of project-based learning in higher education: Student outcomes and measures. International Journal of Educational Research, 102, 101586.

[10]. Krajcik, J. S., \& Czerniak, C. M. (2018). Teaching science in elementary and middle school: A projectbased learning approach. Routledge.

[11]. Wilhelm, J., Sherrod, S., \& Walters, K. (2008). Project-based learning environments: Challenging preservice teachers to act in the moment. The Journal of Educational Research, 101(4), 220-233.

[12]. Terziev, V. (2020). New strategy for higher education for 2021-2030 in Bulgaria and challenges for its implementation. 60th International Scientific Conference on Economic and Social Development XX International Social Congress (ISC 2020), 60, pp. 67-75. Moscow.

[13]. Mettivier, G., Bliznakova, K., Sechopoulos, I., Boone, J. M., Di Lillo, F., Sarno, A., ... \& Russo, P. (2017). Evaluation of the BreastSimulator software platform for breast tomography. Physics in Medicine \& Biology, 62(16), 6446.

[14]. Bliznakova, K., Russo, P., Mettivier, G., Requardt, H., Popov, P., Bravin, A., \& Buliev, I. (2015). A software platform for phase contrast x-ray breast imaging research. Computers in biology and medicine, 61, 62-74. 